\title{
ТЕХНОЛОГИЯ ОЧИСТКИ И РЕЦИКЛИНГА БУРОВОГО РАСТВОРА
}

\author{
Третьяк Александр Александрович1, \\ 13050465@mail.ru
}

\author{
Яценко Елена Альфредовна', \\ tksiww@yandex.ru

\section{Борисов Константин Андреевич1, 13020165@mail.ru}

\author{
Карельская Екатерина Витальевна ${ }^{1}$, \\ karelskaya_1992@mail.ru \\ 1 Южно-Российский государственный политехнический университет (НПИ) им. М.И. Платова,
Россия, г. Новочеркасск, ул. Просвещения, 132.
}

\begin{abstract}
Актуальность исследования обусловлена тем, что бурение скважин является основным видом работ при разведке нефртегазовых георесурсов. При этом, по оценке специалистов, ежегодно образуется более 5 миллионов м³ бурового шлама, из которого только 4 \% перерабатывается для нужд производства. Проблема выделения шлама из бурового раствора и его переработка в настоящее время стоит остро как никогда. Выполненные экспериментальные исследования позволили установить влияние постоянного магнитного поля на буровой раствор и на содержание твердой фазы, а также на структуру образца высушенной корки. Выполненные исследования химического состава буровых шламов Морозовского и ВосточноЧумаковского месторождений Краснодарского края позволили разработать технологию и рекомендовать изготовление пропанта непосредственно в полевых условиях, на месторождении.

Цель: разработать эффрективную технологию очистки и рециклинга бурового раствора и предложить способ получения пропанта непосредственно на участках буровых работ.

Объекты: скважины, сооружаемые при разведке георесурсов на Морозовском и Восточно-Чумаковском месторождении Краснодарского края.

Методы: экспериментальные исследования бурового раствора с целью улучшения качества его очистки, лабораторные исследования состава шлама и рециклине для получения пропанта.

Результаты. Решение поставленных задач позволило предложить эфффективную схему очистки бурового раствора с использованием устройства для омагничивания в постоянном магнитном поле. Выявлен механизм ускорения выпадения бурового шлама в осадок. Изучение раствора под микроскопом позволило выявить кластерные структуры, способствующие увеличению вязкости раствора на 20 \%, снижению водоотдачи до двух раз, увеличению интенсивности выноса шлама на поверхность и снижению коррозии до 30 \%. Установлено время релаксации бурового раствора - в течение 20 часов после омагничивания в постоянном магнитном поле напряженностью 2200 эрстед.
\end{abstract}

\section{Ключевые слова:}

Буровой шлам, очистка бурового раствора, омагничивание, рециклине, получение пропанта, геоэкология.

\section{Введение}

Бурение скважин является основным видом работ при разведке георесурсов. Основной объем работ приходится на бескерновое бурение с помощью долот различной конструкции. Ежегодно в России буровые организации бурят несколько тысяч скважин различного назначения и различной глубины, при этом образуются миллионы кубических метров бурового шлама.

Несмотря на большое количество разработок в области использования буровых отходов, исследования и опытно-промышленные работы в этой области остаются актуальными до настоящего времени. Известно, что буровой шлам оказывает негативное воздействие на геоэкологическую систему ввиду сложного минералогического состава, содержания в нем нефтепродуктов и токсичных химических добавок [1-3]. Таким образом, разработка технологии использования отходов бурения, образующихся при сооружении нефтегазовых скважин, или так называемый рециклинг, является актуальной научной задачей. Развитие промышленности стимулирует рост объемов буровых работ на углеводородное сырье, что оказы- вает негативное воздействие на геологическую систему ввиду получения большого количества бурового шлама [4-6]. По оценке специалистов, объем бурового шлама составляет более 5 млн м ${ }^{3}$ в год, при этом доля переработки бурового шлама не превышает 4 \% в год [7-9].

Государственные экологические и надзорные службы ежегодно ужесточают экологические требования к утилизации отходов, образующихся при сооружении нефтегазовых скважин, поэтому нефтегазовые компании в последнее время уделяют большое внимание решению этих вопросов.

Буровые растворы, используемые при бурении скважин Морозовского и Восточно-Чумаковского месторождения Краснодарского края, имеют сложную структуру и реологические свойства. Применяют в основном полимер-бентонитовые буровые растворы на основе лигносульфатов, имеющие следующий состав: бентонит (30-40 кг/ $\left.{ }^{3}\right), \mathrm{Na}_{2} \mathrm{CO}_{3}\left(1,0-2,0 \kappa \Gamma / \mathrm{m}^{3}\right)$, $\mathrm{NaOH}\left(1,0 \mathrm{\kappa г} / \mathrm{M}^{3}\right)$, КССБ $\left(10-20\right.$ кг $\left./ \mathrm{M}^{3}\right)$, КМЦ $500\left(1-3 \mathrm{\kappa г} / \mathrm{M}^{3}\right)$,

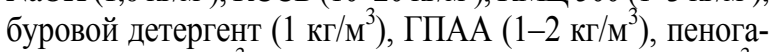
ситель $\left(0,3 \kappa \mathrm{m}^{3}\right)$, смазывающая добавка $\left(3-6 \kappa \Gamma / \mathrm{M}^{3}\right)$. 
Данные буровые растворы на заключительном этапе

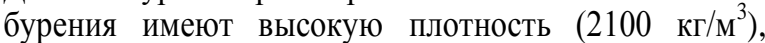
большие значения статистического (30-40/60-90 дПа) и динамического напряжения сдвига (30-40 Па.с). Буровые растворы с таким составом необходимы для безаварийного бурения скважин в рассмотренных геологических условиях $[10,11]$.

Исходя из вышеизложенного, была предложена технология обработки бурового раствора постоянным магнитным полем как для улучшения реологических свойств бурового раствора, так и с целью увеличения процента выхода бурового шлама на поверхность. В целом предложенный способ обработки бурового раствора направлен на уменьшение зашламованности скважины буровыми отходами.

В ходе экспериментальных исследований было выявлено влияние постоянного магнитного поля на буровой раствор. Прежде всего, была установлена зависимость толщины полимерглинистой корки от содержания твердой фазы (рис. 1).

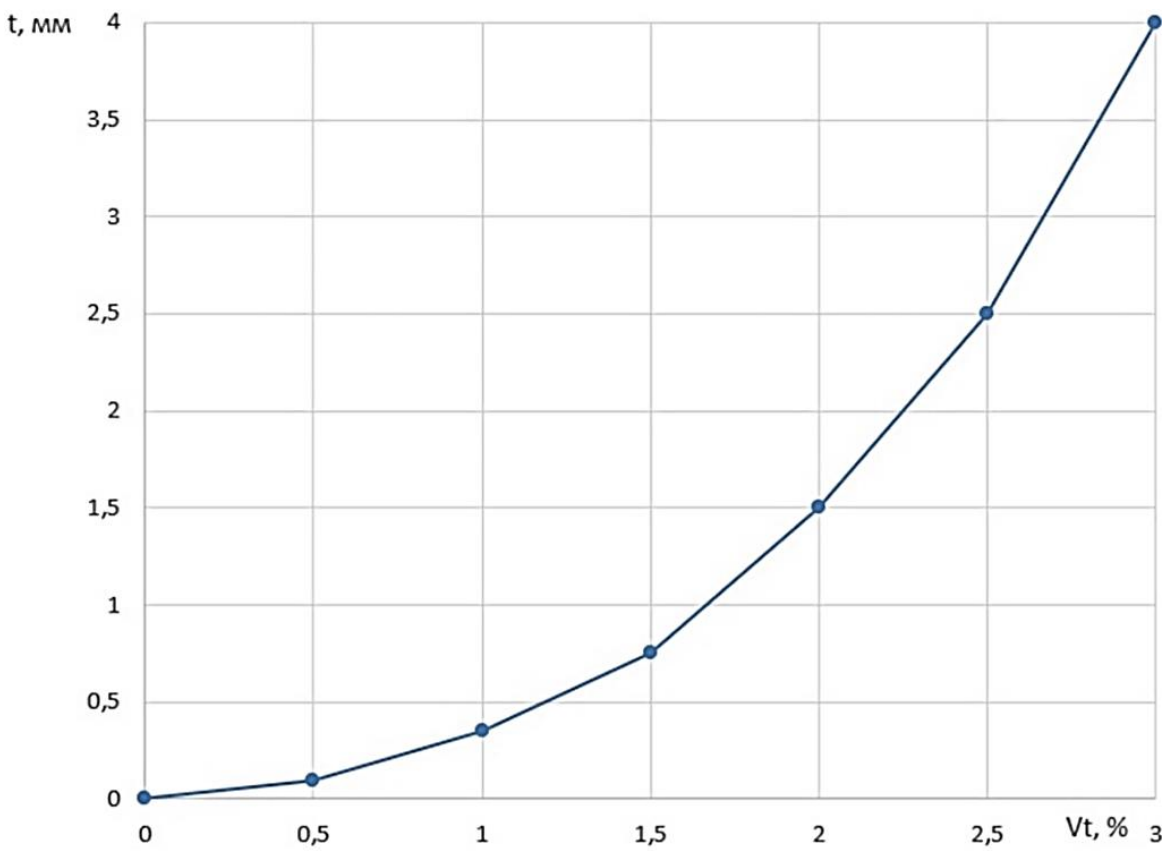

Рис. 1. Влияние содержания твердой фазы $\left(V_{t}, \%\right)$ на толщину полимерглинистой корки $(t$, мм)

Fig. 1. Influence of the solid phase content $\left(V_{t}, \%\right)$ on the thickness of the polymer clay crust $(t, m m)$

Основными объектами исследований были полимерные корки буровых растворов, полученные на приборе ВМ-6, после их высушивания [10-13]. Изучение высушенных корок производилось на микроскопе QUANTA 200 (рис. 2-4).

Изучение высушенных корок бурового раствора под микроскопом до и после омагничивания показывает, что происходит необратимая коагуляция бурового шлама.

Pис. 2. Структура высушенного образиа корки бурового раствора, увеличенная в $10^{9}$ раз: 1 - частицы глины; 2 - частицы песка; 3 - агрегаты коллоидных частии; 4 - агрегаты коллоидных частич высокой степени агрегации

Fig. 2. Structure of the dried drilling mud sample, enlarged by $10^{9}$ times: 1 - clay particles; 2 - sand particles; 3 - aggregates of colloidal particles; 4 - aggregates of colloidal particles with high degree of aggregation
Во время обработки бурового раствора в постоянном магнитном поле с напряженностью 2200 эрстед частицы шлама коагулируют между собой, укрупняются и, как результат, происходит ускорение до 30 \% выпадения шлама в осадок. При этом образуются коллоидные структуры в виде молекул-диполей (рис. 5) и, как результат, водоотдача бурового раствора уменьшается в два раза, а вязкость увеличивается на 20 \%.

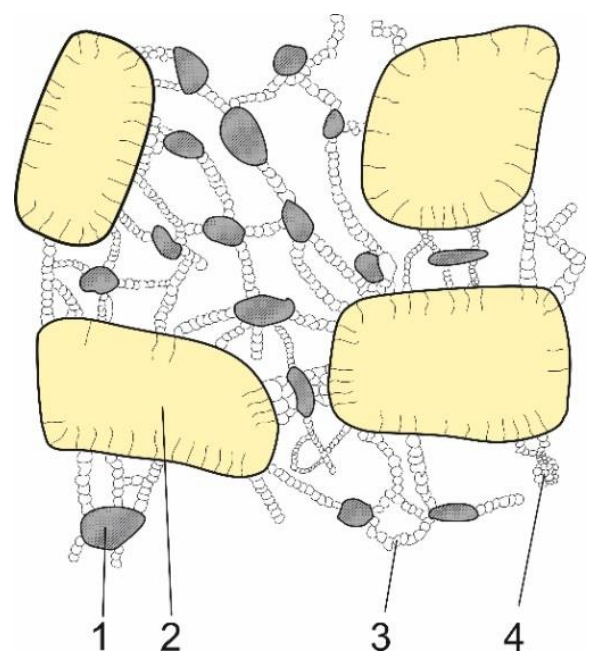




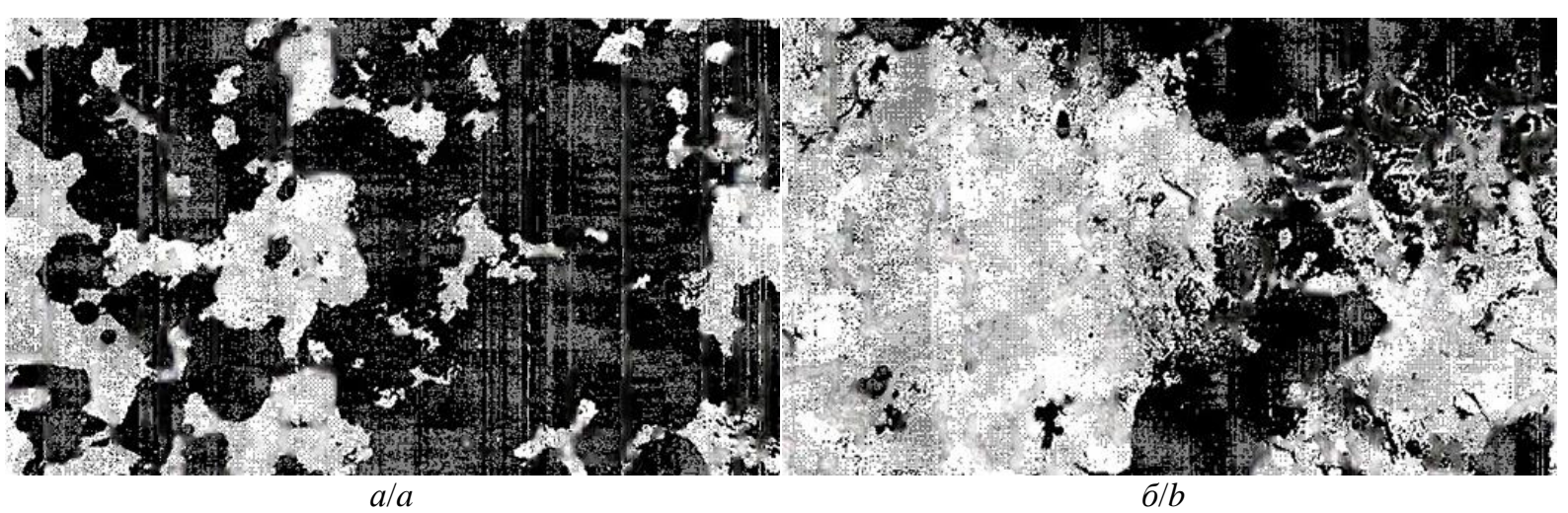

Рис. 3. Фотографии фильтрационной корки бурового раствора в процессе бурения, увеличенные в $1,9 \times 10^{4}$ раз: а) до магнитной обработки; б) после магнитной обработки

Fig. 3. Photos filter cake of drilling mud while drilling, increased by $1,9 \times 10^{4}$ times: a) before magnetic treatment; b) after magnetic treatment
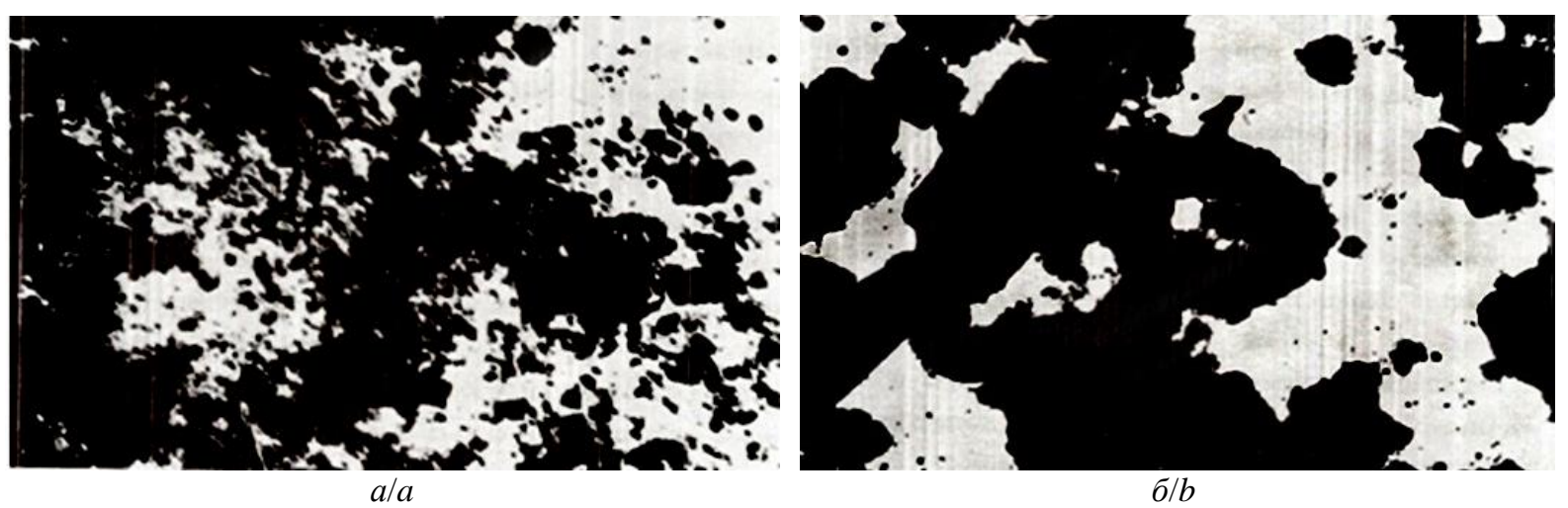

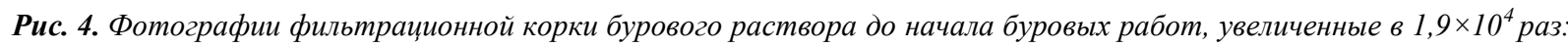
a) до магнитной обработки; б) после магнитной обработки

Fig. 4. Photos filter cake of drilling mud before drilling, increased by $1,9 \times 10^{4}$ times: a) before magnetic treatment; $b$ ) after magnetic treatment
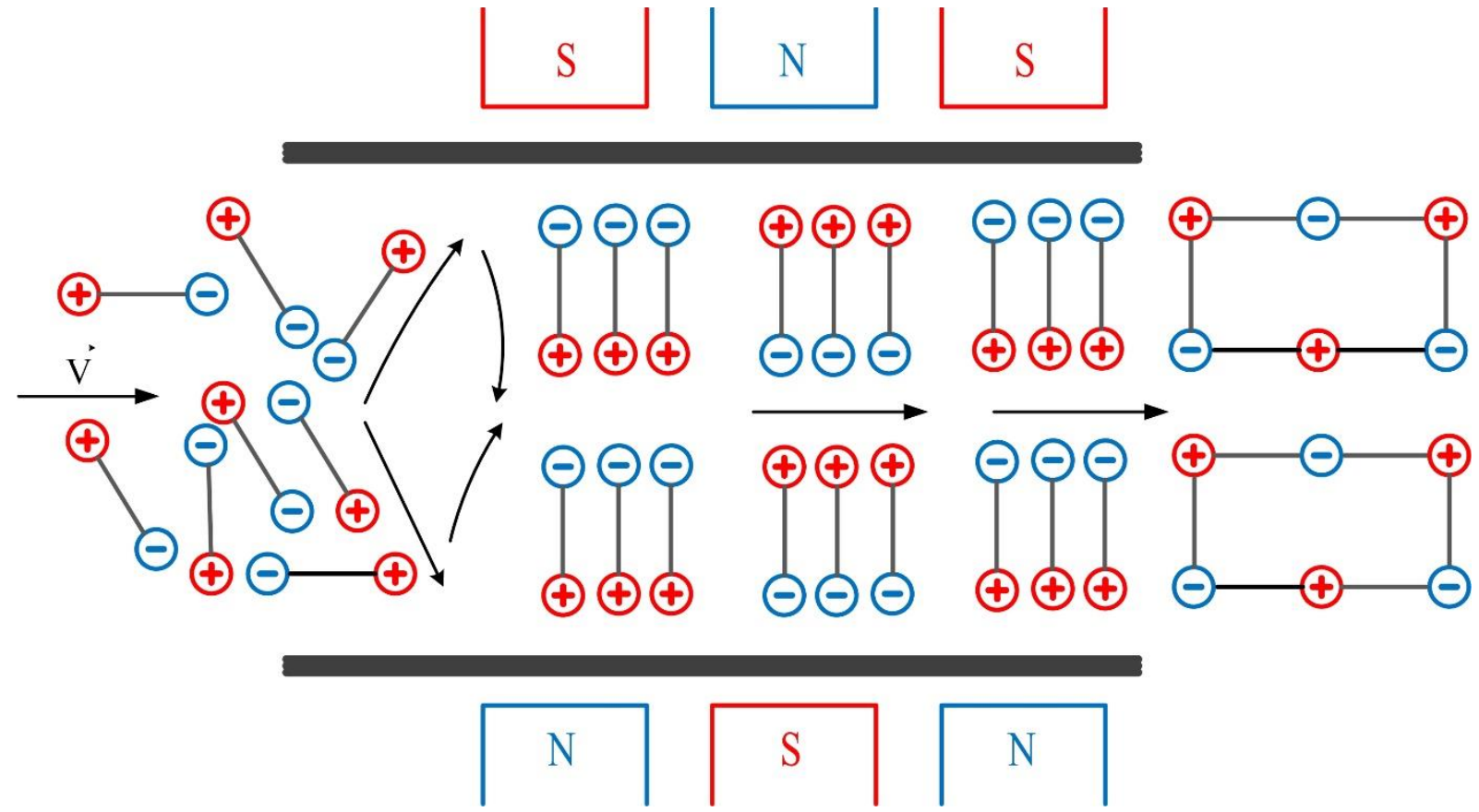

Рис. 5. Схема кластерных структур бурового раствора при прохождении его через постоянное магнитное поле

Fig. 5. Diagram of cluster structures of drilling mud when it passes through a constant magnetic field 
Таким образом, структурообразование за счет дипольного взаимодействия в коллоидном растворе является главным, определяющим.

Описанная картина изменений структуры и свойств раствора под влиянием магнитного поля может быть использована при расчетах параметров и выборе приборов, применяемых для омагничивания [11, 13-15].

Лабораторно-экспериментальные исследования выполнялись при напряженности 2200 эрстед, скорости пропускания бурового раствора $0,3 \mathrm{M} / \mathrm{c}$, температуре $20{ }^{\circ} \mathrm{C}$. Время обработки бурового раствора в устройстве для омагничивания составляло 40 минут в замкнутом цикле.

Как показывают экспериментальные опыты, время «памяти» обработанного раствора и характер релаксационной зависимости (рис. 6) изменяются во времени. В течение 24 часов омагниченный буровой раствор теряет свои свойства. Исходя из этого, предлагается омагничивание раствора на буровой установке выполнять в замкнутом цикле. С целью решения обозначенных выше проблем нами предложена схема омагничивания промывочной жидкости в замкнутом цикле, которая показана на рис. 7.

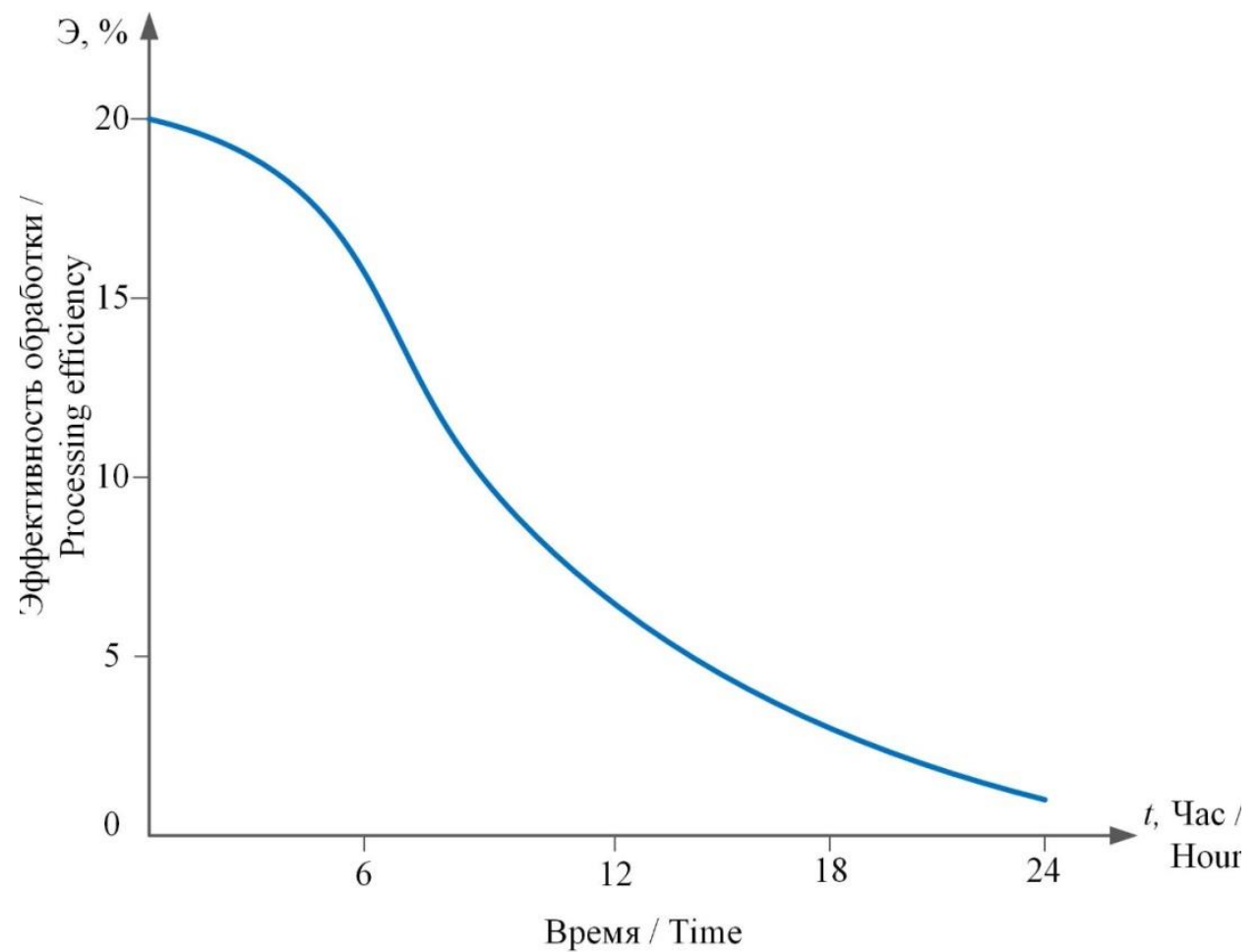

Рис. 6. Релаксационная кривая омагничивания бурового раствора

Fig. 6. Relaxation curve of drilling fluid magnetization

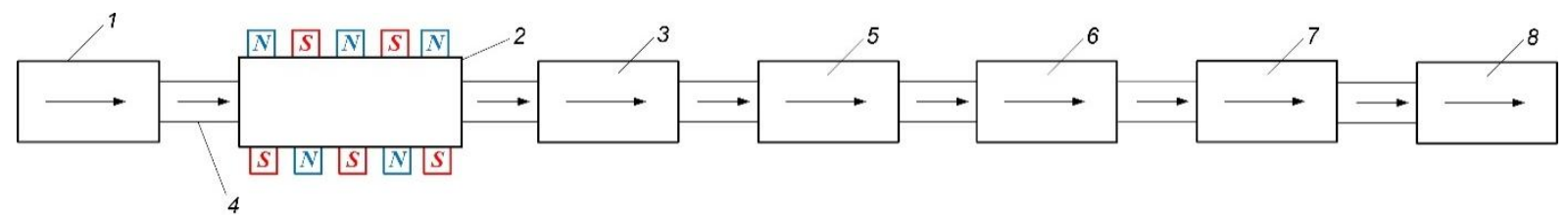

Pис. 7. Схема омагничивания промывочной жидкости в замкнутом ијике: 1 - буровой насос; 2 - блок омагничивания; 3 - нагнетательный шланг; 4 - манифольд; 5 - вертлюг-сальник; 6 - ведущая бурильная труба; 7 - бурильная труба; 8 - долото

Fig. 7. Scheme of magnetization of the washing liquid in a closed cycle: 1 -drilling pump; 2 - magnetization unit; 3 -discharge hose; 4 -manifold; 5 -swivel oil seal; 6-lead drill pipe; 7 -drill pipe; 8 -chisel

Нами впервые на установке для омагничивания было установлено, что воздействие постоянным магнитным полем существенно меняет параметры промывочных жидкостей. На способ обработки бурового раствора и устройство для его обработки была подана заявка на изобретение и получен патент RU № 2255199.

С целью возможного применения бурового шлама для производства пропанта были выполнены лабораторные исследования физико-химических, минерало- гических и биологических свойств образцов отобранного шлама на Морозовском и ВосточноЧумаковском месторождениях Краснодарского края. Концепция оксидов в буровом шламе определялась на вакуумном спектрометре.

Для определения фазового состава образцы буровых шламов Морозовского и Восточно-Чумаковского месторождений были исследованы с помощью рентгеновского порошкового дифрактометра ARL XTRA 
(Thermo Fisher Scientific). Интерпретация полученных данных проводилась с использованием базы данных ICDD (The International Center for Diffraction Data).

Анализ рентгенограмм Морозовского и ВосточноЧумаковского месторождений показал, что основной фазой в исследуемом буровом шламе является кварц $\left(\mathrm{SiO}_{2}\right)$, находящийся в количестве около 11-30 \%. Другими же фазами являются монтмориллонит $\left(\mathrm{Al}_{2} \mathrm{O}_{3} \cdot 4 \mathrm{SiO}_{2} \cdot \mathrm{H}_{2} \mathrm{O} \cdot \mathrm{pH}_{2} \mathrm{O}\right)$, содалит $\left(3 \mathrm{Na}_{2} \mathrm{O} \cdot 3 \mathrm{Al}_{2} \mathrm{O}_{3} \cdot 6 \mathrm{SiO}_{2} \cdot 2 \mathrm{NaCl}\right)$, барит $\left(\mathrm{BaSO}_{4}\right)$ и кальцит $\left(\mathrm{CaCO}_{3}\right)$. Наличие данных веществ в составе бурового шлама говорит о возможности его использовании при синтезе качественных пропантов.

Наиболее важным для синтеза алюмосиликатных пропантов является наличие в буровом шламе кварца.

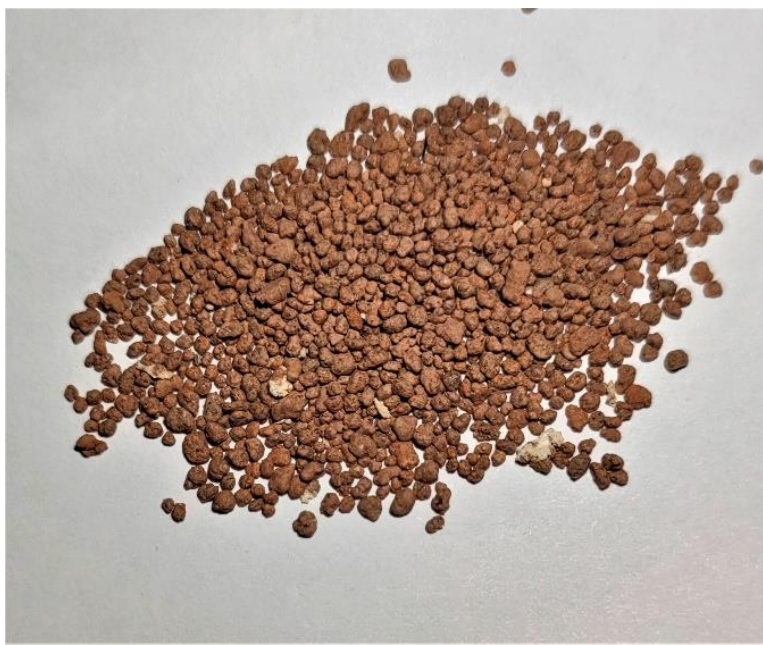

Pис. 8. Внешний вид пропанта (температура спекания $\left.1000{ }^{\circ} \mathrm{C}\right)$

Fig. 8. Proppant appearance (sintering temperature $1000{ }^{\circ} \mathrm{C}$ )
На рис. 8, 9 представлен внешний вид образцов пропанта, полученного из бурового шлама при температуре спекания 1000 и $900{ }^{\circ} \mathrm{C}$ соответственно.

Таким образом, выполненные лабораторноэкспериментальные исследования позволили разработать и предложить технологию рециклинга бурового шлама непосредственно в полевых условиях, на месторождении, с использованием попутного газа для обжига пропанта. Технологическая схема универсального перерабатывающего буровой шлам комплекса показана на рис. 10 [16-18].

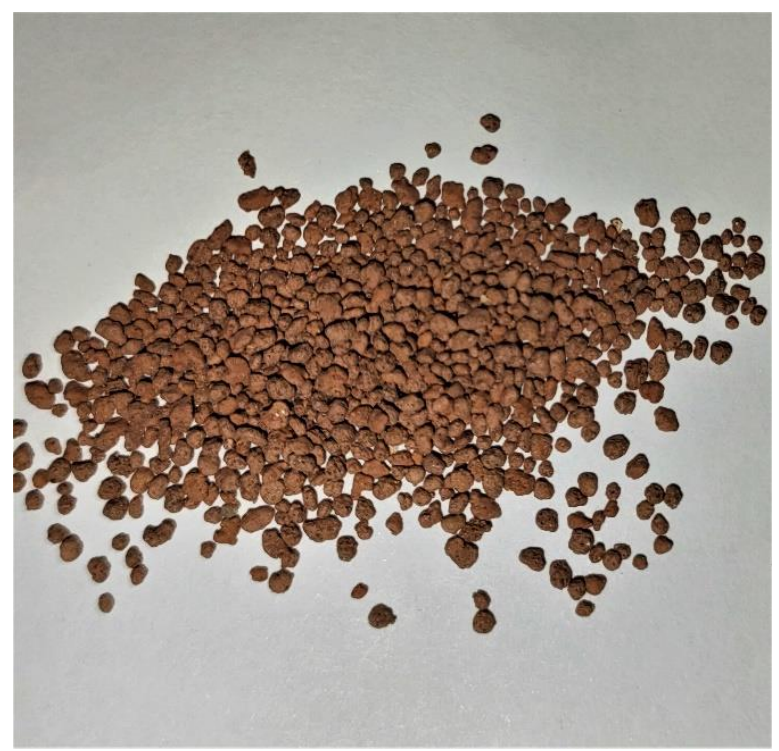

Pис. 9. Внешний вид пропанта (температура спекания $\left.900{ }^{\circ} \mathrm{C}\right)$

Fig. 9. Proppant appearance (sintering temperature $900{ }^{\circ} \mathrm{C}$ )

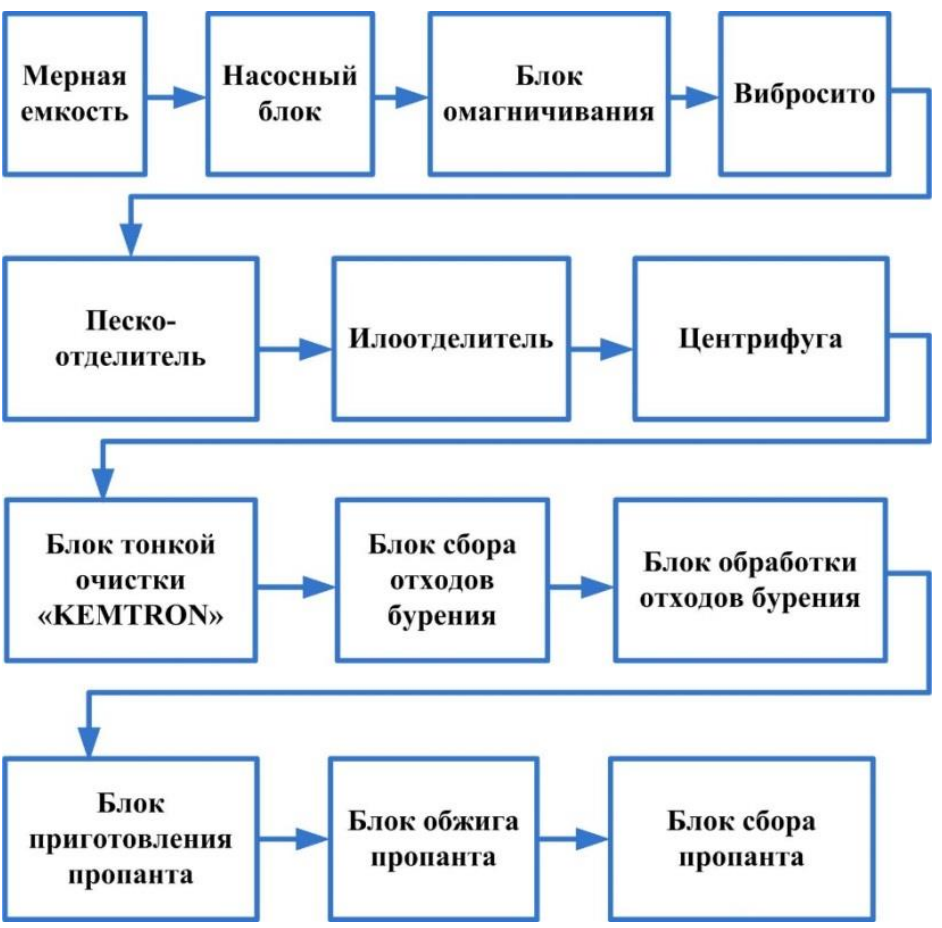

Рис. 10. Технологическая схема универсального перерабатывающего буровой илам комплекса

Fig. 10. Technological scheme of the universal processing drilling mud complex 
Внедрение универсального перерабатывающего буровой шлам комплекса непосредственно в полевых условиях позволит получить качественный пропант из бурового шлама, при этом решаются вопросы рекультивации, обжига, транспортировки и хранения пропанта.

Выполненный экономический анализ предлагаемой технологии обработки бурового раствора показал, что при расчете экономической эффективности в разных регионах необходимо учитывать районный коэффициент цен на услуги по утилизации отходов, образующихся при сооружении скважин различного назначения [19-22].

\section{Выводы}

Выполненные экспериментальные исследования бурового раствора и бурового шлама, отобранного на бурящихся скважинах в Краснодарском крае, позволили сделать следующие выводы:

- воздействие на буровой раствор постоянным магнитным полем в замкнутом цикле омагничивания способствует увеличению вязкости до 20 \%, снижению водоотдачи до 2-х раз, увеличению интенсивности выпадения шлама до $30 \%$;

- исследуемый буровой раствор, омагниченный в постоянном магнитном поле напряженностью 2200 эрстед, удерживает магнитные свойства до 24 часов;

- обобщены и систематизированы результаты исследований по синтезу алюмосиликатных пропантов, выполнены оценки фазового, химического, минералогического и гранулометрического составов буровых отходов, получаемых при сооружении скважин Морозовского и ВосточноЧумаковского месторождений;

\section{СПИСОК ЛИТЕРАТУРЫ}

1. Cobb M., Irvine M., Fichera M. Gas development, drill cuttings disposal - best practicable environmental option. - Edinburgh: ERM Worldwide Group Ltd, 2019. - 38 p.

2. Caenn R., Darley H.C.H., Gray R.G. Chapter 14. Drilling and drilling fluids waste management // Composition and properties of drilling and completion fluids (7th ed.). - Cambridge: Gulf Professional Publishing, 2017. - P. 597-636.

3. Environmental fates and effects of ocean discharge of drill cuttings and associated drilling fluids from offshore oil and gas operations / D. Sanzone, J. Neff, D. Lewis, N. Vinhateiro, J. Blake // IOGP Report 543. - March 2016. - P. 4-10.

4. Идентификация отходов бурения и их использование А.А. Третьяк, Е.А. Яценко, С.А. Онофриенко, Е.В. Карельская // Известия Томского политехнического университета. Инжиниринг георесурсов. - 2021. - Т. 332. - № 2. - С. 36-43.

5. Влияние добавок металлургического шлама на процессы синтеза пропантов на основе буровых шламов / Е.А. Яценко, Б.М. Гольцман, А.А. Третьяк, А.А. Чумаков // Черные металлы. - 2021. - № 8. - С. 49-53.

6. Hasan A.R., Kabir C.S. Two-phase flow in vertical and inclined annuli // International Journal of Multiphase Flow. - March 1992. - V. 18 (2). - P. 279-293.

7. Губа А.С., Плетнева Н.И., Явич М.Ю. Идентификация отходов бурения // Нефть, газ, новации. - 2019. - № 11. - С. 82-86.

8. Матвиенко В.В., Кузнецова В.А., Цеханский М.В. К вопросу о современных методах переработки и утилизации отходов бурения // Нефть и газ Сибири. - 2017. - № 3 (28). - С. 147-151.

9. Третьяк А.Я., Рыбальченко Ю.М. Теоретические исследования по управлению буровым раствором в осложненных усло-
- разработаны рекомендации по использованию отходов бурения Морозовского и ВосточноЧумаковского месторождений для изготовления пропантов с целью гидравлического разрыва пласта;

- использование бурового шлама позволит получить дополнительный источник сырьевых материалов для алюмосиликатных пропантов и сократить количество отходов при сооружении нефтегазовых скважин;

- применение отходов бурения при синтезе эффективных алюмосиликатных пропантов позволит минимизировать техногенное воздействие буровых нефтегазовых компаний на окружающую среду, а также сократить расходы на содержание отходов на полигонах, высвободить и вернуть в хозяйственный оборот значительные площади земельных угодий, занимаемые отвалами;

- разработаны технологические основы для создания и выпуска легкого, прочного, а также востребованного в настоящее время пропанта;

- предлагаемые разработки по технологии очистки и рециклингу бурового шлама позволяют решить проблему обращения с отходами непосредственно на участках буровых работ, что даст значительный экономический и экологический эффект для буровых компаний

Работа выполнена в ЮРГПУ (НПИ) при финансовой поддержке Российского научного фонда в рамках Соглашения № 20-79-10142 «Разработка эффективной технологии синтеза алюмосиликатных пропантов с использованием отходов бурения нефтегазовых скважин Южного федерального округа» (руководитель А.А. Третьяк).

виях // Известия высших учебных заведений СевероКавказский регион. Технические науки. Приложение. 2006. - № 7. - С. 56-61.

10. Буровой раствор для строительства скважин в сложных условиях / А.А. Третьяк, Ю.М. Рыбальченко, С.И. Лубянова, Ю.Ю. Турунтаев, К.А. Борисов // Нефтяное хозяйство. 2016. - № 2. - С. 28-31.

11. Высокоингибированный буровой раствор: пат. Рос. Федерация, № 2303047, заявл. 05.10.06; опубл. 20.07.07. Бюл. № 20. $6 \mathrm{c}$.

12. Применение физических полей для регулирования свойств буровых растворов и тампонажных материалов / Н.М. Шерстнёв, С.П. Шандин, С.И. Толоконский, Н.О. Черская, А.В. Уголева // Российский химический журнал. - 1995. - № 5. T. 39. - C. 22-26.

13. Hudgins C.M. Jr. Chemical use in North Sea oil and gas E\&P // Journal of Petroleum Technology. - January 1994. - V. 46 (01). P. 67-74.

14. Осипов Ю.Б. Поведение глинистых суспензий в магнитном поле // Геология. - 1964. - Сер. № 4. - С. 15-19.

15. О некоторых особенностях влияния электромагнитного поля на движение ионов в потоке раствора / В.К. Погодин, Ю.Я. Голгер, В.И. Классен, П.А. Смыслов // Применение магнитной обработки воды в энергетике. Материалы Всесоюзного совещания. - Новосибирск, 1967. - С. 20-24.

16. Буровой раствор и управление его реологическими свойствами при бурении скважин в осложненных условиях / В.Ф. Чихоткин, А.Я. Третьяк, Ю.М. Рыбальченко, М.Л. Бурда // Бурение на нефть. - 2007. - № 7-8. - С. 58-60.

17. Differential-sticking mechanisms and a simple wellsite test for monitoring and optimizing drilling mud properties / P.I. Reid, G.H. Meeten, P. Clark, B.D. Chambers, A. Gilmour, M.W. Sanders // 
SPE Drilling \& Completion. - June 2000. - V. 15. - № 15 (2). P. 97-104. DOI: 10.2118/64114-PA.

18. Наноструктурированный, высокоингибированный буровой раствор: пат. Рос. Федерация, № 2708849, заявл. 24.01.19; опубл. 12.12.19. Бюл. № 35. -8 с.

19. Можжерин А.В., Коржавин А.Ю. Исследование остаточной проводимости алюмосиликатных и магнезиально-кварцевых пропантов при циклических нагрузках // Бурение и нефть. 2017. - № 5. - C. 42-45.
20. Можжерин А.В., Коржавин А.Ю. Керамический пропант или песок? // Сфера. Нефть и газ. - 2018. - № 1. - С. $92-95$.

21. BP p.l.c Statistical Review of World Energy 2019. 68th ed. - UK: Pureprint Group Limited, 2019. - 61 p.

22. Prospects for the use of drilling slurries for the synthesis of alummosihcate propants / E. Yatsenko, A. Tretyak, A. Chumakov, D. Golovko // Materials Today: Proceedings. - 2021. - V. 38. P. 4. - P. 1886-1888. DOI: $10.1016 /$ j.matpr.2020.08.575.

Поступила 24.12.2021 2.

\section{Информация об авторах}

Tретьяк A.A., доктор технических наук, доцент, профессор кафедры нефтегазовой техники и технологий Южно-Российского государственного политехнического университета (НПИ) им. М.И. Платова.

Яценко $\boldsymbol{E}$. тов Южно-Российского государственного политехнического университета (НПИ) им. М.И. Платова.

Борисов К.A., кандидат технических наук, доцент кафедры нефтегазовой техники и технологий ЮжноРоссийского государственного политехнического университета (НПИ) им. М.И. Платова.

Карельская $\boldsymbol{E}$.В., ассистент кафедры нефтегазовой техники и технологий Южно-Российского государственного политехнического университета (НПИ) им. М.И. Платова. 
UDC 622.24

\title{
DRILLING MUD CLEANING AND RECYCLING TECHNOLOGY
}

\author{
Alexander A. Tretyak' \\ 13050465@mail.ru
}

Elena A. Yatsenko ${ }^{1}$, tksiww@yandex.ru

Konstantin A. Borisov ${ }^{1}$, 13020165@mail.ru

\section{Ekaterina V. Karelskaya ${ }^{1}$,} karelskaya_1992@mail.ru

1 M.I. Platov South-Russian State Polytechnic University (NPI), 132, Prosveshcheniya street, Novocherkassk, Russia.

The relevance of the study is caused by the fact that well drilling is the main type of work in the exploration of oil and gas geo-resources. At the same time, according to experts, more than 5 million $\mathrm{m}^{3}$ of drilling mud is formed annually, of which only $4 \%$ is processed for production needs. The problem of sludge extraction from drilling mud and its processing is now more acute than ever. The experimental studies made it possible to establish the effect of a constant magnetic field on a nanostructured highly inhibited drilling mud and on the content of the solid phase, as well as on the structure of the dried crust sample. The performed studies of the chemical composition of drilling mud from the Morozovsky and Vostochno-Chumakovsky deposits of the Krasnodar region allowed us to develop a technology and recommend the production of propant directly in field environment.

Goal: to develop an effective technology for cleaning and recycling drilling mud and to propose a method for obtaining propane directly at drilling sites.

Objects: wells constructed during exploration of geo-resources at the Morozovsky and Vostochno-Chumakovsky deposits of Krasnodar region.

Methods: experimental studies of drilling mud in order to improve the quality of its purification, laboratory studies of the composition of sludge and recycling to obtain proppant.

Results. The solution of the tasks set allowed us to propose an effective scheme for cleaning drilling mud using a device for magnetization in a constant magnetic field. The mechanism of acceleration of drilling sludge precipitation has been revealed. The study of the solution under a microscope revealed cluster structures that contribute to the increase in the viscosity of the solution by $20 \%$, decrease in water loss by up to two times, increase in the intensity of sludge removal to the surface and decrease in corrosion by up to $30 \%$. The relaxation time of the drilling mud - within 20 hours after magnetization in a constant magnetic field with a strength of 2200 oersted - was established.

\section{Key words:}

Drilling returns, drilling mud cleaning, magnetization, recycling, proppant production, geo-ecology.

The research was carried out at the SRSPU (NPI) and financially supported by the Russian Science Foundation within the agreement no. 20-79-10142 «Development of the effective technology of the synthesis of aluminosilicate propants using the oil and gas well drilling wastes in Southern Federal District» (project leader A.A. Tretyak).

\section{REFERENCES}

1. Cobb M., Irvine M., Fichera M. Gas development, drill cuttings disposal - best practicable environmental option. Edinburgh, ERM Worldwide Group Ltd., 2019. 38 p.

2. Caenn R., Darley H.C.H., Gray R.G. Ch. 14 - Drilling and drilling fluids waste management. Composition and Properties of Drilling and Completion Fluids $\left(7^{\text {th }}\right.$ ed.). Cambridge, Gulf Professional Publ., 2017. pp. 597-636.

3. Sanzone D., Neff J., Lewis D., Vinhateiro N., Blake J. Environmental fates and effects of ocean discharge of drill cuttings and associated drilling fluids from offshore oil and gas operations. IOGP Report 543, March 2016. pp. 4-10.

4. Tretyak A.A., Yatsenko E.A., Onofrienko S.A., Karelskaya E.V Identification of drilling waste and their use. Bulletin of the Tomsk Polytechnic University. Geo Assets Engineering. 2021, vol. 332, no. 2. pp. 36-43. In Rus.

5. Yatsenko E.A., Goltsman B.M., Tretyak A.A., Chumakov A.A. Influence of metallurgical cuttings additives on proppant synthesis processes based on drill cuttings. Chernye Metally, 2021, no. 8, pp. 49-53. In Rus.

6. Hasan A.R., Kabir S. Two-phase flow in vertical and inclined annuli. International Journal of Multiphase Flow, March 1992, no. 18 (2), pp. 279-293.
7. Guba A.S., Pletneva N.I., Yavich M.Yu. Drilling waste identification. Oil, gas, innovations, 2019, no. 11, pp. 82-86. In Rus.

8. Matvienko V.V., Kuznetsova V.A., Tsekhansky M.V. About the issue of modern methods of processing and disposal of drilling waste. Oil and Gas of Siberia, 2017, no. 3, pp. 147-151. In Rus.

9. Tretyak A.Ya., Rybalchenko Yu. M. Theoretical research on drilling fluid management in complicated conditions Izvestiya of higher educational institutions. North Caucasian region. Technical science. Application, 2006, no. 7, pp. 56-61. In Rus.

10. Tretyak A.A., Rybalchenko Yu.M., Lubyanova S.I., Turuntaev Yu.Yu., Borisov K.A. Drilling fluids for the construction of wells in complex conditions. Oil industry, 2016, no. 2, pp. 28-31. In Rus.

11. Tretyak A.Ya., Mnatsakanov V.A., Zaretsky V.S., Shamanov S.A., Frolov P.A., Chikhotkin V.F., Rybalchenko Yu.M. Vysokoingibirovanny burovoy rastvor [Highly inhibited drilling mud]. Patent RF, no. 2303047, 2007.

12. Sherstnev N.M., Shandin S.P., Tolokonsky S.I., Cherskaya N.O., Ugoleva A.V. Primenenie fizicheskikh poley dlya regulirovaniya svoystv burovykh rastvorov i tamponazhnykh materialov [Application of physical fields to control the proper ties of drilling fluids and grouting materials]. Rossiyskiy khimicheskiy zhurnal, 1995, vol. 39 , no. 5 , pp. $22-26$ 
13. Hudgins C.M. Jr. Chemical use in North Sea oil and gas E\&P. Journal of Petroleum Technology, January 1994, vol. 46 (01), pp. 67-74.

14. Osipov Yu.B. Povedenie glinistykh suspenziy v magnitnom pole [Behavior of clay suspensions in a magnetic field]. Geologiya, 1964, no. 4, pp. 15-19.

15. Pogodin V.K., Golger Yu.Ya., Klassen V.I. O nekotorykh osobennostyakh vliyaniya elektromagnitnogo polya na dvizhenie ionov v potoke rastvora [On some features of electromagnetic field influence on the movement of ions in the flow of solution]. Primenenie magnitnoy obrabotki vody $v$ energetike. Materialy Vsesoyuznogo soveshchaniya [Application of magnetic water treatment in power engineering. Materials of the All-Union meeting]. Novosibirsk, 1967. pp. 20-24.

16. Chikhotkin V.F., Tretyak A.Ya., Rybalchenko Yu.M., Burda M.L Drilling fluid and control of its rheological properties when drilling wells in difficult conditions. Drilling for oil, 2007, no. 7-8, pp. 58-60. In Rus.

17. Reid P.I., Meeten G.H., Clark P., Chambers B.D., Gilmour A., Sanders M.W. Differential-sticking mechanisms and a simple wellsite test for monitoring and optimizing drilling mud properties. SPE Drilling \& Completion, June 2000, vol. 15 , no. 15 (2), pp. 97-104. DOI: 10.2118/64114-PA.

18. Tretyak A.A., Onofrienko S.A. Nanostrukturirovanny, vysokoingibirovanny burovoy rastvor [Nanostructured, highly inhibited drilling mud]. Patent RF, no. 2708849, 2019.

19. Mozzherin A.V., Sakulin A.V., Skurikhin V.V. Korzhavin A.U. Studies of the residual conductivity of alumino-silicate and magnesian-quartz proppants under cyclic loads. Drilling and Oil, 2017, no. 5, pp. 42-45. In Rus.

20. Mozhzherin A.V., Korzhavin A.Yu. Ceramic proppant or sand? Sphere. Oil and gas, 2018, no. 1, pp. 92-95. In Rus.

21. BP p.l.c Statistical Review of World Energy 2019. $68^{\text {th }}$ ed. UK, Pureprint Group Limited, 2019. 61 p.

22. Yatsenko A.E., Tretyak A., Golovko D. Prospects for the use of drilling slurries for the synthesis of alummosihcate propants. $M a-$ terials Today: Proceedings, 2021, vol. 38, P. 4. pp. 1886-1888.

Received: 24 December 2021.

\section{Information about the authors}

Alexander A. Tretyak, Dr.Sc., professor M.I. Platov South Russian State Polytechnic University (NPI).

Elena A. Yatsenko, Dr.Sc., professor, head of the General chemistry and technology of silicates department, M.I. Platov South Russian State Polytechnic University (NPI).

Konstantin A. Borisov, Cand. Sc., associate professor, M.I. Platov South-Russian State Polytechnic University (NPI). Ekaterina V. Karelskaya, assistant, M.I. Platov South-Russian State Polytechnic University (NPI). 